Diterbitkan oleh Program Studi IImu Komunikasi

Universitas Ahmad Dahlan Yogyakarta

\title{
MEMAHAMI PEMBAJAKAN DIGITAL DALAM BUDAYA MENGOPI VIDEO DI WARNET ${ }^{1}$
}

\author{
Oleh: Irham Nur Anshari
}

Departemen Ilmu Komunikasi UGM

E-mail: irham.anshari@gmail.com

\begin{abstract}
In recent years, copying digital video (film or television program) has become a daily practice insome internet cafes in Yogyakarta. This paper departs from research aimed atdocumenting the practice of copying the video and its implications as a contribution in understanding digital piracy. By using ethnographic approach, informants in this studyis the actors of copying video in the internet cafe. This study found that digital piracy occurs because it has been the culture of a society to access the media as effectively as possible with the development of media technology.
\end{abstract}

Keywords: Digital Piracy, Copy Culture, Internet Cafe, Video.

\begin{abstract}
Abstrak
Dalam beberapa tahun terakhir, mengopi video digital (film atau program televisi) telah menjadi praktik sehari-hari pada beberapa warung internet (warnet) di Yogyakarta. Tulisan ini berangkat dari penelitian yang bertujuan mendokumentasikan praktik mengopi video tersebut beserta implikasinya sebagai sumbangsih dalam memahami pembajakan digital. Dengan menggunakan pendekatan etnografi, informan dalam penelitian ini adalah para pelaku budaya mengopi atau pengopi video di warnet. Penelitian ini menemukan bahwa pembajakan digital terjadi karena telah adanya kultur dalam sebuah masyarakat untuk mengakses media seefektif mungkin seiring perkembangan teknologi media.
\end{abstract}

Kata Kunci: Pembajakan Digital, Budaya Mengopi, Warnet, Video.

\section{A. Pendahuluan}

Setidaknya sejak tahun 2010, terdapat suatu aktivitas baru pada beberapa warung internet (warnet) di Yogyakarta. Beberapa warnet seolah beralih fungsi dari tempat yang sebelumnya hanya menyediakan layanan koneksi internet, menjadi penyedia data multimedia yang dapat dikopi oleh konsumen warnet. Data multimedia tersebut antara lain: video (film, program/serial televisi), musik, game, aplikasi komputer, dan ebook.

1 Versi awal tulisan ini dipresentasikan pada Konferensi Kajian Komunikasi, Budaya, dan Media "CCCMS 2014" , 10-11 Desember 2014 yang diselenggarakan oleh Program Studi Ilmu Komunikasi Universitas Islam Indonesia. 
Jika sebelumnya konsumen warnet harus mengunduh sendiri data-data tersebut dengan menggunakan jasa koneksi warnet, kini konsumen bisa langsung mengopi (to copy) data yang ditawarkan dengan hanya membayar jasa warnet dalam tarif hitungan waktu. ${ }^{2}$

Peneliti mendapati bahwa alih fungsi warnet ini membentuk budaya baru pada konsumen warnet. Konsumen datang ke warnet untuk mengopi beberapa data menggunakan alat penyimpan data (harddisk eksternal atau flashdisk) untuk mereka akses di rumah ataupun tempat lain. Peneliti menyebut budaya baru di warnet ini sebagai budaya mengopi. Joe Karaganis dan Lennart Renkema (2014) mendefinisikan budaya mengopi sebagai aktivitas mengopi, membagi, atau mengunduh musik, film, acara TV, dan media digital lainnya.

Dalam penelitian ini, peneliti memilih fokus pada budaya mengopi data video. Warnet menawarkan data video yang dipilah dalam folder-folder yang tertata rapi sesuai kategori jenis dan wilayah produksi video. Beberapa kategori tersebut antara lain: Film Barat, Film Asia, Film Indonesia, Film Klasik, Film 3D (tiga dimensi), Serial TV Barat, dan Serial TV Asia. Tiap satu film atau serial TV, biasanya dikumpulkan dalam satu folder bersama dengan poster, sinopsis, dan subtitle dalam bahasa Inggris dan Indonesia.

Wacana peran warnet dalam praktik konsumsi dan distribusi video adalah wacana global yang muncul satu dekade terakhir sebagai tantangan industri film dan video. Di Cina misalnya, dibicarakan bagaimana warnet-warnet seolah telah berubah menjadi bioskop mini karena menawarkan banyak film untuk ditonton. Pada tahun 2010, China Film Copyright Association (CFCA) membuat kebijakan agar warnet membayar iuran per bulan karena telah menjadi tempat memutar film-film China (Xueqing, 2012). Sementara di Selandia Baru, diberitakan bagaimana kepolisian setempat merazia warnet-warnet yang diduga menawarkan film bajakan dalam jumlah yang besar. Seiring meningkatnya akses internet di rumah-rumah, warnet di Selandia Baru berjuang mencari cara untuk menarik konsumen. Beberapa warnet mencoba menambahkan jasa dengan memenuhi server mereka dengan film dan musik yang diperoleh secara ilegal dari internet, menawarkan konsumen akses "all-you-can-eat" dengan bayaran yang murah (Moses, 2013).

Dengan mengaitkan praktik di tingkat lokal dan wacana di tingkat global dalam paparan di atas, peneliti merumuskan beberapa pertanyaan penelitian sebagai berikut: (1) Bagaimana transisi budaya mengonsumsi video yang dilakukan oleh para pengopi video di warnet? (2) Bagaimana perkembangan budaya mengopi video di warnet sejak kemunculannya hingga kini? (3) Apa implikasi budaya mengopi video tersebut terhadap akses para pengopi pada industri distribusi video lain?

Menggunakan pendekatan etnografi, peneliti melakukan penelitian terhadap 10 orang pengopi atau pelaku budaya mengopi video di warnet selama kurun waktu 2 tahun (antara Juli 2013 - Juli 2015). Para pengopi dipilih berdasarkan intensitas ke warnet yang tinggi (lebih dari sekali tiap bulan) dan lamanya melakukan budaya mengopi video di warnet (lebih dari satu tahun). Pengumpulan data dalam penelitian ini dilakukan melalui tiga cara: observasi, wawancara (kelompok dan personal), dan pemeriksaan dokumen (koleksi video yang dikopi). Sebagai pelengkap informasi partisipan, penelitian ini juga

\footnotetext{
${ }^{2}$ Pada saat penelitian ini dilakukan (2013-2015), tarif akses internet adalah Rp 4000-6000 per jam.
} 
Diterbitkan oleh Program Studi IImu Komunikasi

Universitas Ahmad Dahlan Yogyakarta

meneliti database warnet sebagai aspek penting berlangsungnya budaya mengopi video. Peneliti memilih tiga warnet yang intensif dikunjungi oleh pelaku budaya mengopi yang menjadi informan penelitian ini, yaitu S-Net, P-Net, dan L-Net. ${ }^{3}$ Metode pencarian data di warnet hanya berupa pemeriksaan dokumen (koleksi video di warnet).

\section{B. Pembajakan Digital: Sebuah Tinjauan Pustaka}

Kajian-kajian yang membicarkan budaya mengopi lebih banyak meletakkannya sebagai bentuk pembajakan digital. Salah satu kajian penting mengenai pembajakan digital yang meliputi budaya mengopi adalah kajian yang diinisiasi oleh Social Science Research Council (SSRC) dan tertuang dalam Media Piracy in Emerging Economies (Karaganis, 2011). Kajian komprehensif ini mengumpulkan tulisan dari beberapa kelompok riset di Bolivia, India, Mexico, Rusia, Afrika Selatan, dan Brasil selama lebih dari empat tahun. Kajian ini menarik karena tidak hanya mengkaji dari negara berkembang, tetapi juga mengaburkan batasan disiplin dengan melihat praktik pembajakan dari sudut pandang kombinasi hukum, ekonomi, sosial dan budaya.

Peneliti mencatat setidaknya proyek kolaboratif dan komprehensif dalam kajian pembajakan dikembangkan dalam dua proyek berikutnya: dalam Piracy Cultures yang diinisiasi oleh Castels dan Cardoso (2012) serta special issue dalam jurnal Convergence dengan editor Robert Jewitt dan Majid Yar (2013, 19:3). Dalam editorial Jewitt dan Yar"Consuming the illegal: Situating Piracy in Everyday Experience", mereka menyatakan penolakan pada dugaan simplistik pada pembajakan. Dugaan simplistik tersebut menurut mereka merupakan sebuah wacana moralisasi koheren yang membatasi diskusi nilai ekonomi dari konsumen "baik" sebagai oposisi dari konsumen "yang menyimpang". Jewitt dan Yar juga menyatakan penolakan pada kuasa simbolik untuk menyatakan "haram" dan layak hukum pada pembajakan sebagai aktivitas sehari-hari (2013: 1). Dengan membuat kompilasi artikel, jurnal tersebut berkontribusi dalam debat kritis mengenai bentuk konsumsi di mana pembajakan dapat dilihat sebagai praktik dan pengalaman sehari-hari.

Lawrence Lessig adalah salah satu penulis yang intens membicarakan pembajakan dari perspektif hukum dan ekonomi. Pemikirannya banyak dipakai dalam kajian-kajian pembajakan misalnya artikel Ian Condry (2004)“Cultures of Music Piracy: An Ethnographic Comparison of the US and Japan". Condry menggunakan kategorisasi Lessig dalam budaya mengopi untuk menganalisis bahwa hanya pembajakan komersil yang mengacaukan pasar, sedangkan mengunduh sampel musik justru mendukung seniman. Dalam Free Culture (2004: 19), Lessig membuka tulisannya dengan menyatakan bahwa sekarang ini kita sedang berada di tengah-tengah "perang" lainnya terhadap "pembajakan". Internetlah yang memprovokasi perang ini karena internet memungkinkan persebaran konten yang efisien. Misalnya pada praktik yang disebutnya sebagai peer-to-peer (proses berbagi file ke sesama pengguna). Dengan menggunakan

\footnotetext{
${ }^{3}$ Dengan alasan privasi informasi, nama-nama warnet dan konsumen warnet (informan) dalam artikel ini ditulis menggunakan nama samaran.
} 
kecerdasan tersebar (distributed intelligence), sistem ini memudahkan proses berbagi konten yang tidak pernah terbayang di generasi sebelumnya.

Fokus Lessig dalam bukunya tersebut adalah bagaimana dengan relasi baru antara perkembangan jaringan komunikasi teknologi dan konten berhak cipta, hukum tidak hanya mengontrol kreativitas dari pencipta komersial, tetapi juga berdampak pada kreativitas semua orang. Manfaat hukum ini menjadi tidak berbanding dengan kerugian yang ditimbulkannya. Dari sini, Lessig menawarkan perlunya untuk memahami penggunaan konten berhak cipta dan menempatkan pertarungan yang disebut "pembajakan" tersebut dalam konteksnya yang sesuai. Salah satu argumen penting Lessig adalah mengenai kompleksitas file-sharing (yang juga berlaku dalam budaya mengopi) bahwa tidak semua proses berbagi benar-benar menyalahi hak cipta. Jika kemudian hukum menyatakan seluruh proses berbagi ini sebagai aktivitas yang ilegal, ada beberapa aktivitas lain yang akan turut terkena dampak hukum ini. Baginya perlu diperhitungkan lagi seberapa jauh kerugian yang ditimbulkan dari aktivitas berbagi yang tumbuh sejalan dengan perkembangan teknologi informasi.

Dalam buku berikutnya "Remix: Making Art and Commerce Thrive in the Hybrid Economy" (2008), Lessig mencoba mengembangkan pemikirannya mengenai subjek yang ia bahas empat tahun sebelumnya dalam buku Free Culture (2004). Lessig (2008: 289) mengatakan bahwa teori ekonomi di balik hak cipta membenarkannya sebagai alat untuk berurusan dengan apa yang disebut para ekonom sebagai "the problem of positive externalities". Positive externality adalah sebuah efek dari perbuatan seseorang kepada orang lain, misalnya ketika seseorang menyetel musik cukup keras, orang di sekitarnya juga bisa mendengarkan musik tersebut. Internet dan digitalisasi membuat positive externality semakin mudah menyebar. Jika seseorang memiliki file video, dengan satu klik seseorang lain bisa memilikinya.

Lessig setidaknya adalah akademisi pertama yang menggagas untuk memandang pembajakandalam konteks kontemporer tidak secara sempit sebagai praktik "negatif". Baginya alih-alih melabeli pembajakan sebagai kriminal, perlu dilakukan tinjauan ulang pada hukum hak cipta. Atau dalam bahasanya sesuai sub judul bukunya, perlu adanya tinjauan pada bagaimana media besar memakai teknologi dan hukum untuk membatasi budaya dan mengontrol kreativitas. Majid Yar dalam artikelnya "The Rethoric and Myth of Anti-Piracy Campaign: Criminalization, Moral Pedagogy, and Capitalist Property Relation in the Classroom" (2008) seolah mewarisi pemikiran Lessig ini dengan menggambarkan bagaimana kampanye-kampanye anti pembajakan mereproduksi ideologi kepemilikan kapitalis.

Pemahaman yang diajukan Karaganis (2011) maupun Lessig (2004, 2008) menawarkan perspektif lebih luas dari definisi konvensional pembajakan sehingga dapat membantu dalam meneropong budaya mengopi. Namun, riset dengan teori ini masih cukup problematis. Meski sudah mempertimbangkan perspektif dari pelaku pembajakan (ekonomi lokal yang rendah, perubahan cepat konsumen dan praktik kultural), media dalam definisi ini seringkali masih dimaknai sebagai komoditas belaka. Pemaknaan sempit media ini bisa menjebak dalam melihat pembajakan dalam bingkai yang selalu menguntungkan pelaku (konsumen media) dan merugikan produser media. Untuk itu teori-teori dalam perspektif ini hanyalah pintu masuk meninjau pembajakan digital dalam 
Diterbitkan oleh Program Studi IImu Komunikasi

Universitas Ahmad Dahlan Yogyakarta

budaya mengopi video di warnet. Perspektif ini menjadi penting hanya ketika digunakan dalam konteks sebagai kritik pada wacanan dominan mengenai pembajakan digital sebagai perilaku ilegal belaka.

\section{Temuan Data dan Pembahasan}

\section{Transisi Budaya Mengakses Video}

Berbeda dari aktivitas download serta filesharing secara online di mana proses distribusi media berjalan dalam dunia cyber, dalam budaya mengopi video di warnet ini proses distribusi dapat dilacak dalam ruang sosial yang konkret. Meskipun video dalam budaya mengopi di warnet ini tidak memiliki bentuk fisik seperti keping VCD/DVD, aliran distribusi media tetap dapat dipetakan. Dengan kata lain, budaya mengopi di warnet adalah bentuk sirkulasi media digital di era internet yang lebih visible.

Dari penelitian terhadap para pengopi video di warnet di Yogyakarta, peneliti menemukan bahwa sebelum kemunculan warnet, ada dua aktivitas yang berkembang sebagai bentuk budaya konsumsi video. Pertama, budaya menyewa video di rental. Budaya ini seringkali dianggap sebagai pembajakan karena beberapa video (VCD/DVD, film atau serial) yang disewakan seringkali bukanlah produk resmi dari distributor video. Budaya menyewa ini setidaknya lebih dominan di kalangan anak muda Yogyakarta daripada membeli VCD/DVD baik produk resmi ataupun produk bajakan.

Budaya yang kedua adalah men-download atau mengunduh video di internet. Seperti halnya di wilayah atau tempat lain, budaya ini berkembang seiring tawaran internet dengan berbagai media digital baik yang resmi ataupun bajakan. Seperti dibahas sebelumnya, budaya ini lebih sulit untuk dipetakan dalam konteks wilayah karena berada dalam ruang-ruang personal dalam jaringan dunia cyber. Mengunduh sendiri video di warnet, khususnya film dan serial yang memiliki durasi panjang, membutuhkan koneksi internet yang tinggi dan waktu yang cukup relatif panjang dibanding mengopi secara offline.

Para pengopi memiliki alasan masing-masing mengapa beralih dari budaya menyewa VCD/DVD di rental video ke budaya mengopi video di warnet. Salah satunya adalah alasan ekonomi di mana mengopi video di warnet tidak meletakkan harga satuan pada video. Warnet hanya meletakkan harga akses per jam dengan harga sekitar 40006000 rupiah per jam. Dengan waktu akses ini, pengopi bisa mengopi video sesuai keinginan mereka tanpa adanya biaya tambahan. Saat penelitian ini dibuat, biaya untuk menyewa satu VCD-DVD berkisar antara 3000-5000 rupiah per judul.

Selain ekonomi, peralihan teknologi menjadi salah satu alasan. Soni, salah satu pengopi, misalnya beralih dari rental VCD/DVD karena ia kemudian lebih banyak menonton di laptop (notebook) yang tidak memiliki pemutar VCD/DVD. Menonton data digital dalam medium penyimpan data seperti harddsik external atau flashdisk jadi pilihan untuk menonton di laptop. Beberapa alasan lain peralihan dari rental ke warnet mengacu pada kualitas video rental (terutama video bajakan) yang sulit untuk memenuhi standar penonton. Seperti diungkapkan oleh beberapa pengopi di bawah ini: 
Aku dulu nge-rental, serialnya update juga. Hanya kadang-kadang dulu itu subtitlenya ada yang Bahasa Malaysia. Tapi tidak ada pilihan [untuk mengganti sendiri subtitle]. Dulu misalnya aku nonton serial $\mathrm{H}-2$ pakai subtitle Bahasa Malaysia. Begitu ada warnet, aku kopi lagi serial itu. (Mulya)

VCD DVD bajakan kemungkinan di Indonesia itu satu sumbernya. Jadi kalau kamu menemukan satu film rusak di tengah-tengah, di tempat [rental video] lain sama rusaknya. Satu sumber kayaknya. Kalau di warnet kita bisa dapat kualitas HD (High Definition)/Blu-Ray Rip yang tidak bisa didapat di pedagang VCD DVD. (Anto)

Perkembangan jaringan komunikasi internet yang menawarkan akses film-film tidak berbayar membuat beberapa penyewa rental sempat beralih ke budaya mengunduh atau men-download video. Namun dengan mengunduh video di internet, para pengunduh membutuhkan kapasitas internet yang cepat. Di Yogyakarta (dan secara umum di Indonesia), internet dengan kecepatan tinggi masih merupakan barang mewah dan eksklusif. Sebagai gambaran, untuk berlangganan internet di rumah membutuhkan harga minimal sekitar 50.000 rupiah untuk kecepatan minimal.

Beberapa pengopi di warnet sebelumnya mengalami kendala ketika mengunduh video menggunakan koneksi internet di rumah. Alternatif lain yaitu mengunduh video di kantor atau ruang publik lain (seperti kafe) yang menawarkan akses internet dengan kecepatan tinggi. Namun kecepatan ini dianggap tetap tidak seefisien mengopi video di warnet. Seperti yang diungkapkan oleh para pengopi sebagai berikut:

Dulu kalau tidak mengopi punya teman ya download. Aku ke warnet karena tidak bisa download dan kelamaan download, jadi mengopi saja. Kalau pengen download yang size-nya besar itu pertama lama, kedua belum tentu bisa. Kamu bisa tinggalin tidur ternyata tetap gagal download-nya. (Anto)

Aku hobinya mengikuti serial barat yang keluar tiap minggu. Dulu waktu di Jakarta, aku harus menghabiskan waktu untuk download. Aku biasa download di kantor yang internetnya cepat. Waktu download dulu aku jarang bahkan nyaris tidak pernah download film, karena berat. Kalau serial kan durasinya paling 20 menit. (Nadia)

\section{Perkembangan Budaya Mengopi Video di Warnet}

Jika kita mendeskripsikan budaya mengopi video di warnet sebagai aktivitas mengopi video digital dari database warnet, budaya ini sebenarnya bukanlah sebuah budaya yang baru dan dapat ditemui di berbagai daerah. Setidaknya sejak awal kemunculan warnet di Indonesia, beberapa warnet menyediakan database untuk menyimpan data hasil unduhan para konsumen, termasuk data video. Perkembangan teknologi penyimpan data dengan kapasitas tinggi yaitu flashdisk dan harddisk external telah memungkinkan konsumen warnet untuk mengopi video di warnet, tanpa perlu mengunduh sendiri.

Di Yogyakarta, sejak lebih dari sepuluh tahun, aktivitas mengopi video di warnet telah dilakukan dalam skala kecil. Tapi sejak separuh dekade terakhir aktivitas ini menjadi masif dan mulai diperbincangkan ketika munculnya warnet yang memiliki 
Diterbitkan oleh Program Studi IImu Komunikasi

Universitas Ahmad Dahlan Yogyakarta

database sangat besar. Soni menceritakan bagaimana awalnya pada tahun 2010 menemukan database film dan serial yang sangat banyak di Warnet M-Net. Warnet MNet pada saat itu menawarkan beragam video baik yang populer maupun yang klasik, yang tidak pernah ia temui di warnet lain. Meskipun letak warnet jauh dari tempat tinggalnya tapi ia merasa puas karena bisa mendapatkan banyak video yang beragam.

Beberapa warnet dengan database video yang banyak ini kemudian ditemui di beberapa warnet lain. Setidaknya ketika penelitian ini dibuat ada 7 warnet di Yogyakarta yang ditemukan peneliti dengan sistem multimedia yang sama dengan M-Net yaitu: JNet, D-Net, C-Net-, P-Net, S-Net, serta L-Net. Maksud peneliti dengan sistem multimedia yang sama ini merujuk pada jumlah koleksi video yang banyak dan updatenya yang serentak di warnet-warnet tersebut. Beberapa pengopi menyebutnya jaringan warnet ini sebagai warnet jaringan M-Net.

Kehadiran warnet jaringan M-Net membuat para pengopi beralih dari mengopi video di warnet lain dengan berbagai alasan. Dari titik inilah budaya mengopi di warnet mulai terlihat masif. Seiring perkembangannya, warnet-warnet lain di luar jaringan MNet mulai menjadikan koleksi data multimedia sebagai nilai jual warnet. Meski demikian warnet jaringan M-Net menjadi yang paling sering dibicarakan. Adanya pelevelan warnet oleh para pengopi dapat dilihat dari ucapan beberapa pengopi sebagai berikut:

Dulu sempat aku ke PlaNet [warnet di luar jaringan M-Net] waktu P-Net updatenya mentok. Running man dulu sempat P-Net tidak update. Di PlaNet tetap update walaupun kualitasnya jelek. Di sana filmnya yang kecil-kecil [ukuran kualitas]. Harddisk-nya mungkin cuma delapan giga. Walaupun ada film-film tertentu yang ada di PlaNet tetapi tidak ada di P-Net, tapi karena di PlaNet kualitasnya jelek jadi aku tetap request di P-Net. (Ucok)

Aku awalnya tahu [jaringan M-Net] dari mengopi [video] di teman. Aku tanya teman mengopinya di mana? 'Di warnet P-Net.' Mulailah menular. Sebenarnya sudah pernah dengar dari beberapa orang kalau PlaNet tidak ada apa-apanya dari P-Net. Terus waktu aku ke P-Net awalnya aku lihat langsung membatin 'kacau-kacau', PlaNet tidak ada apa-apanya. Kalau PlaNet parah banget [folderingnya], ya udah [videonya] terhampar begitu, tidak ada klasifikasi abjad. Kalau di P-Net klasifikasi per abjad aja udah banyak banget. Jauh databasenya, primitif [PlaNet] ini. (Nadia)

Dengan tawaran untuk mengopi video sebanyak yang diinginkan, beberapa pengopi tidak memiliki agenda rutin untuk ke warnet. Berbeda dengan menyewa video di rental di mana para penyewa maksimal hanya bisa menyewa tiga hingga lima judul video sekali datang. Dan harus kembali ke rental untuk mengembalikan dalam jangka waktu satu sampai tujuh hari. Namun tingkat update video di warnet yang cepat seringkali menggugah para pengopi untuk rutin datang ke warnet. Seperti yang diungkapkan oleh para pengopi sebagai berikut:

Kalau dibilang berapa sering sih aku lebih tergantung koleksi di harddisk. Kalau sudah nonton semua filmnya, karena aku pada dasarnya suka nonton atau kadang-kadang aku suka random kepikiran ngumpulin film-film tertentu 
ya aku ke warnet. Jadi lebih tidak teratur sih, tidak mesti sebulan tiga kali atau gimana. (Dina)

Setiap minggu setidaknya sekali aku ke warnet. Paling maksimal lima jam, setidaknya tiga jam. (Mulya)

Beberapa pengopi menggunakan harddisk external untuk mengopi video di warnet. Beberapa yang lain menggunakan flashdisk. Semua bergantung pada kebutuhan banyaknya video yang dikopi. Nadia misalnya mengungkapkan bahwa masih cukup dengan flashdisk 32 GB, karena ia ke warnet seminggu sekali. Sementara Soni yang tinggal di dua kota (Yogyakarta dan Jakarta), setiap pulang ke Jogja biasanya meminjam harddisk teman untuk mengopi video stok selama di Jakarta. Stok video ini terlalu besar untuk dikopi hanya menggunakan flashdisk.

Kualitas video menjadi salah satu pertimbangan saat memilih video yang ingin dikopi. Namun alat penyimpan data, baik harddisk external ataupun flashdisk juga turut menjadi pertimbangan ketika mengopi video di warnet. Semakin bagus kualitas sebuah video, semakin besar kapasitas yang dibutuhkannya. Karena itu tiap-tiap pengopi akan mempertimbangkan kebutuhannya ketika mengopi, seperti yang terangkum dalam percakapan berikut:

Tidak usah yang besar-besar size-nya, menuh-menuhin harddisk. Mending yang kualitas kecil tapi dapat banyak film dan serial daripada kualitas bagus tapi cuma dapat sedikit tontonan. (Soni)

Aku kalau mengopi dua: yang versi HD sama yang kecil. Yang HD untuk ditonton kalau yang kecil untuk disimpan. (Ucok)

Menonton video dalam data digital softfile membuat video dan subtitle atau terjemahan terletak secara terpisah. Dalam hal ini tidak semua subtitle cocok dengan video. Beberapa pengopi memilih aktif untuk mencari subtitle yang cocok melalui situssitus online. Sementara beberapa pengopi memilih tidak jadi menonton jika subtitle mengalami masalah. Seperti yang terdokumentasikan dalam wawancara berikut:

Tidak semua subtitle yang ada di warnet, betul sync-nya [sinkronisasi gambar dan teks]. Jadi aku mencari subtitle di situs lain. Kadang-kadang aku nyari yang bahasa Indonesia kalau males mikir. Tapi masalahnya gak semua subber Indonesia benar mengartikannya. Sebagian masih sebatas kamus mengartikannya. (Anto)

Kalau aku biasa cari aja di google subtitle-nya kalau tidak oke. Nanti masuk ke situs-situs tertentu. (Nadia)

Kemudahan memperoleh video secara masif dalam waktu singkat menjadi salah satu implikasi dari budaya mengopi di warnet. Di sini para pengopi berkembang dari sekedar penonton menjadi kolektor. Tidak seperti video dalam keping VCD/DVD, video digital dalam bentuk softfile mampu disimpan secara lebih efisien karena tidak memiliki fisik yang menyita tempat ataupun mudah rusak. Pengoleksian menjadi salah satu pilihan 
Diterbitkan oleh Program Studi IImu Komunikasi

Universitas Ahmad Dahlan Yogyakarta

pengopi agar dapat menonton film tersebut kapan saja. Namun tawaran koleksi warnet membuat koleksi masing-masing tidak terlalu berharga. Perihal mengoleksi ini terucap dalam wawancara berikut:

Semua yang disimpan digital itu cenderung lebih permanen, disimpan dua tahun pun tidak apa-apa. (Mulya)

Aku simpan paling cuma satu atau dua dari yang aku kopi. Yang collectible aja. Misal serial Modern Family yang aku ikutin dari awal sampai terbaru. Aku belum terlalu merasa penting beli harddisk karena aku tahu kalau aku hapus film ini nanti aku bisa ngopi lagi. (Nadia)

Dengan menilik perkembangan praktik budaya mengopi video di warnet di atas, dapat ditemukan adanya penyesuaian yang dilakukan oleh dua pihak. Di satu sisi pihak warnet yang berlomba-lomba menawarkan jasa akses data digital seiring tumbuhnya bisnis "baru" warnet ini. Di sisi lain pihak konsumen video yang mengikuti budaya ini dengan melahirkan praktik-praktik baru dalam mengonsumsi video seperti: memiliki alat penyimpan data digital (harddisk dan flashdisk), memahami atribut vdeo digital (kualitas, subtitle), ataupun mengoleksi video digital.

Sebagai implikasi dari variasi tawaran data digital di internet dan kebutuhan konsumen, warnet tidak hanya menawarkan film-film komersil yang dalam waktu hampir bersamaan tayang di bioskop. Dalam warnet dapat ditemui produk-produk yang sulit diakses secara komersil di luar budaya mengopi ini. Misalnya serial televisi dari stasiun televisi luar negeri, film-film klasik, ataupun film-film independen yang tidak dipublikasikan secara komersil. Tawaran video ini ditempatkan bak etalase di tampilan awal desktop komputer warnet dalam folder yang terkategorisasi secara rapi. Konsumen warnet yang awalnya hanya ingin menggunakan jasa akses internet bukan tak mungkin tergoda untuk menengok etalase dan mengopi video.

\section{Implikasi Budaya Mengopi pada Industri Distribusi Video}

Sejauh penelitian ini dilakukan, warnet dengan tawaran video yang besar baru ditemukan di Yogyakarta. Soni misalnya mengungkapkan ke Yogyakarta tidak lengkap kalau tidak ke warnet. Menurut Soni, biasanya kalau teman-teman di luar kota tahu, mereka akan menitip video untuk dikopikan. Dengan ini, Soni akan ke warnet berbekal sejumlah daftar film dan serial titipan dari teman-teman di luar kota. Budaya yang identik dengan Yogyakarta ini juga membuat beberapa pengopi yang merupakan pendatang di Yogyakarta khawatir akan kehilangan budaya ini bila meninggalkan Yogyakarta. Seperti yang diungkapkan oleh para pengopi sebagai berikut:

Aku kalau pulang teman-temanku pada nanya: 'Serius di Jogja ada gini? Sejamnya berapa warnet?' 'Enam ribu.' [jawabku]. 'Hah serius enam ribu bisa dapat sebanyak ini? Wah gila!' [kata mereka] Menurutku emang fenomenal banget kota Jogja dengan warnetnya ini. Mungkin kalau aku udah pindah dari Jogja yang aku kangenin ya warnet. (Dina) 
Nanti misalnya kalau aku lulus, salah satu yang paling aku kehilangan di Jogja bukan kuliah, tapi warnet. Tidak usah jauh-jauh lulus, sekarang aja kalau pulang liburan aku pasti nyetok [video]. Kalau aku di Medan, download satu video Youtube aja sampai mampus aku nungguin. (Ucok)

Tawaran video yang banyak membuat fokus bisnis warnet di jaringan M-Net ini seolah beralih. Salah satu pengopi misalnya dengan tegas menungkapkan bahwa saat ini, warnet yang tidak menawarkan film di Jogja tidak akan laku. Beberapa pengopi menganggap bahwa bisnis utama dari warnet ini adalah sebagai pusat mengopi video atau data digital lain, seperti yang diungkapkan oleh para pengopi sebagai berikut:

Kalau kita ke P-Net, colokan harddisk yang di depan komputer kan kelihatan udah mau jebol. Bahkan sampai pada buka colokan bagian belakang. Itu berarti udah berapa ratus orang yang mencolok harddisk di situ. Aku juga dulu sempat buka kaca colokan belakang di P-Net. Sebentar lagi di L-Net [warnet yang lebih baru] pasti juga gitu. Yang lucu dulu pernah ada orang dateng ke warnet, terus karena ngantri dia minta operatornya tolong kopikan aja film tertentu. Ya jelas tidak boleh, wong yang mereka jual ya bisnis ngopi film itu. (Mulya)

Selama warnet masih murah, bisnis warnet ini pasti tidak akan mati. Masalahnya biaya warnet kan gak berhubungan sama inflasi, beda sama bisnis makanan atau transportasi yang naik begitu BBM [Bahan Bakar Minyak] naik. Cuma yang bikin ragu, sejauh mana masalah legal dan ilegal bisnis ini ke depannya. (Anto)

Akses pada film di warnet menimbulkan pertanyaan bagaimana implikasi budaya menonton video di warnet ini pada akses penonton terhadap bioskop. Beberapa pengopi mengungkapkan bahwa budaya mengopi ini tidak serta merta menghapus budaya menonton ke bisokop, namun tetap berimplikasi pada keputusan menonton di bioskop. Seperti yang diungkapkan oleh para pengopi sebagai berikut:

Kalau aku ke bioskop ya karena ingin merasakan cinema experience-nya. Gimana sih kalau nonton film ini ramai-ramai dengan orang lain. Aku kalau nonton film-film kopian biasanya sendiri karena kadang tidak enak nonton film tertentu ramai-ramai. Misal ada komentar-komentar penonton lain yang mengganggu. (Mulya)

Aku ke bioskop kalau ingin nonton bareng teman misalnya. Biasanya filmfilm yang canggih spesial effect-nya, yang kalau ditonton di bioskop beda dibanding nonton di rumah. (Nadia)

Pesatnya minat para pengopi pada tawaran warnet dapat dikatakan terkait erat dengan budaya mengakses data digital. Beberapa rental video di Yogyakarta mencoba beradaptasi dengan menawarkan jasa mengopi video dalam bentuk data digital softfile atau tidak dalam keping VCD/DVD dengan sistem tarif per giga dari data yang dikopi. Namun, sistem tarifnya yang memakai hitungan per giga membuat beberapa pengopi di 
Diterbitkan oleh Program Studi IImu Komunikasi

Universitas Ahmad Dahlan Yogyakarta

warnet merasa tawaran ini jauh kalah memuaskan dari warnet. Seperti yang diungkapkan oleh para pengopi sebagai berikut:

Sekarang beberapa rental juga bisa jadi tempat untuk mengopi film. Mereka hitungannya per giga. Jadi kalau kita mengopi berapa giga, nanti pembulatan ke atas berapa giga kali tarif per giga. (Anto)

Sekarang beberapa rental video sudah tutup. Cuma aku masih belum tahu apa itu cuma yang di sekitar sini atau di tempat-tempat lain. Di Bima Sakti [salah satu rental video] bisa juga untuk mengopi video 10 ribu [rupiah] per giga. Ini mahal banget kalau dibandingin warnet yang 10 ribu kita bisa dapat berapa film. (Ucok)

Dari paparan pada bagian ini, dapat kita tinjau bagaimana budaya mengopi video di warnet membuat satu "terobosan" atau karakteristik baru pada cara mengakses video. Secara ekonomi, budaya ini tidak meletakkan nilai ekonomi satuan pada video seperti halnya jika kita menonton di bioskop atau membeli serta menyewa VCD/DVD. Bisnis yang ditawarkan warnet adalah akses database warnet per jam. Meminjam istilah bisnis restoran "all you can eat" di mana pengunjung cukup membayar sekali untuk makan sepuasnya, bisnis warnet ini mungkin tepat disebut dengan istilah "all you can copy".

\section{Kesimpulan}

Distribusi media digital kontemporer berkembang seiring kemajuan jaringan komunikasi, khususnya apa yang ditawarkan oleh internet (Lessig, 2004; 2008). Meskipun praktik konsumsi dan distribusi media digital adalah suatu aktivitas yang bersifat global, pola-polanya seringkali kesulitan untuk ditinjau dalam konteks wilayah empiris karena aktivitas berlangsung dalam ruang-ruang pribadi melalui jaringan internet.

Aktivitas mengopi media digital, khususnya video, di warnet menjadi salah satu contoh menarik bagaimana perkembangan distribusi media digital transnasional yang memanfaatkan teknologi internet namun proses tersebut berada dalam konteks ruang yang nyata dan dapat ditinjau secara empiris. Dalam pola distribusi ini, warnet berada dalam batasan distribusi online dan offline. Sebagai distributor media global ini, warnet tidak memerlukan kesepakatan dengan para produsen media, namun cukup dengan kemampuan koneksi internet yang tinggi.

Dengan meneliti budaya mengopi di warnet, peneliti mencatat beberapa kesimpulan penting. Pertama, dengan memahami aktivitas mengopi video sebagai praktik memperoleh produk video, diperlihatkan bahwa aktivitas mengopi video di warnet merupakan transisi dari setidaknya dua aktivitas sebelumnya yakni menyewa video di rental dan mengunduh video di internet. Dua aktivitas tersebut dianggap kalah efisien dari budaya mengopi video di warnet. Yang menarik dari transisi ini adalah para konsumen tidak semata-mata merupakan pihak yang sebelumnya mengonsumsi produk resmi. Di sini dapat dikatakan bahwa kultur mengkonsumsi produk informal telah ada dalam masyarakat. 
Para pengopi video di warnet bukanlah audiens video yang sebelumnya murni menonton film di bioskop atau membeli video original di toko-toko resmi. Para pelaku budaya mengopi video di warnet ini sebelumnya juga merupakan penyewa video di rental dan pengunduh video di internet, dua aktivitas yang sebenarnya cenderung dikatakan sebagai pembajakan digital juga. Transisi pada aktivitas mengopi di warnet turut berkembang dengan alasan perubahan praktik kultural dan teknologi. Dalam budaya mengopi di warnet ini, pembajakan digital yang ada memungkinkan akses produk media lebih efisien bagi konsumen.

Kedua, penelitian ini juga menemukan bahwa aktivitas mengopi video di warnet sebagai pola baru distribusi media digital berjalan seiring dengan dinamisnya akses konsumen terhadap video. Menonton video di televisi melalui medium VCD/DVD mulai dianggap tidak praktis bagi para pengopi video yang lebih banyak menggunakan medium komputer atau laptop. Di samping itu, data digital pun lebih mudah diolah sesuai keinginan audiens, misal dengan mengganti subtitle sesuai bahasa yang mampu mereka pahami. Dalam hal ini internet memungkinkan persebaran subtitle dalam berbagai bahasa yang pembuatannya seringkali merupakan inisiatif kelompok audiens tertentu (Lihat Lee, 2011; Hu, 2009), sehingga memberikan lebih banyak alternatif video bagi para penonton.

Ketiga, jika sebelumnya produk media dikonsumsi oleh konsumen dengan memberikan keuntungan ekonomi langsung pada produsen (dalam bisnis bioskop atau penjualan keping video), dalam bisnis warnet "all you can copy" ini sulit dipastikan adanya keuntungan yang diperoleh produsen. Sebaliknya dalam bisnis ini warnetlah yang dapat dipastikan memperoleh keuntungan ekonomi secara langsung. Di sini terjadilah rekomodifikasi (proses pembentukan komoditas ulang) produk media. Keuntungan ekonomi langsung tidak dimiliki oleh produsen video melainkan para distributor yang mampu memperoleh dan "menjual ulang" produk media baik dalam hitungan per jam ataupun per giga. Perlu ditinjau lebih dalam lagi apakah rekomodifikasi ini mengancam bisnis distribusi media lain yang legal dan formal, mengingat industri distirbusi video terus berkembang dan mampu beradaptasi dengan perubahan teknologi media, misalnya munculnya pola distribusi Video on Demand atau VOD (lihat Kim \& Park, 2008; Jenner, 2013).

Dalam artikel ini telah ditunjukkan bagaimana budaya mengopi memungkinkan para penonton untuk mengakses produk media secara lebih efisien. Meski demikian terlalu dini untuk melabeli praktik konsumsi dan distribusi ini sebagai ruang demokratisasi media digital yang membuka ruang pada audiens ataupun pengguna media untuk mengatur dan memperoleh apa yang akan mereka konsumsi. Terlalu dini pula menyimpulkan bahwa produsen media adalah pihak yang dirugikan dalam praktik konsumsi dan distribusi ini. Dalam konteks tersebut, peneliti menyarankan perlunya perspektif lain dalam meneropong budaya mengopi video di warnet ini, yakni melihat video sebagai produk kultural yang sarat akan ideologi (lihat Smiers, 2009; Wang, 2003). Dengan memandang video sebagai produk kultural, budaya mengopi di warnet dapat dianalisis lebih jauh dalam konteks relasi kuasa yang mengalir dalam sirkulasi produk media global di era digital. 
Diterbitkan oleh Program Studi IImu Komunikasi

Universitas Ahmad Dahlan Yogyakarta

\section{Daftar Pustaka}

Castells, Manuel dan Gustavo Cardoso. (2012). "Piracy Cultures Editorial Introduction" dalam International Journal of Communication 6 (2012), 826-833

Condry, Ian. (2004). "Cultures of Music Piracy. An Ethnographic Comparison of the US and Japan" dalam International Journal of Cultural Studies Vol 7 (3)

$\mathrm{Hu}$, Kelly. (2009). "Chinese Subtitle Groups and the Neoliberal Work Ethics" dalam Journalism Research 101:177-241

Jenner, Mareike. (2013). "Binge-watching: Video-ondemand, quality TV and mainstreaming fandom" dalam International Journal of Cultural Studies 1-17

Jewitt, Robert dan Majid Yar. (2013). "Consuming the illegal: Situating Piracy in Everyday Experience" dalam Convergence Vol 19(3)

Karaganis, Joe. (Ed.) (2011). Media Piracy in Emerging Economies. New York: Social Science Research Council

Karaganis, Joe dan Lennart Renkema. (2014). Copy Culture in US and Germany (versi daring). Terarsip dalam http://piracy.americanassembly.org/copy-culture-report/ diakses pada 1 April 2014

Kim, Eun-mee \& Sora Park. (2008). "Distributing TV dramas in the digital environment: a Korean case" dalam Asian Journal of Communication Vol. 18(2): 137-154

Lee, Hye-Kyung. (2011). "Participatory Media Fandom: A Case Study of Anime Funsubbing" dalam Media, Culture, \& Society 33(8): 1131-1147

Lessig, Lawrence. (2004). Free culture: How Big Media Uses Technology and the Law to Lock Down Culture and Control Creativity. New York: Penguin Press

Lessig, Lawrence. (2008). Remix: Making Art and Commerce Thrive in the Hybrid Economy. London: The Penguin Press

Moses, Asher. (2013). "Internet Cafes Clean Out after Raid" terarsip dalam http://www.smh.com.au/news/technology/internet-cafes-clean-outafterraid/2008/01/17/1200419959751.html diakses pada 17 Januari 2013

Smiers, Joost. 2009. Arts Under Pressure: Mempejuangkan Keanekaragaman Budaya di Era Globalisasi (terj.). 2009. Yogyakara: Insistpress

Wang, S. 2003. Framing piracy: Globalization and Film Distribution in China. Lanham, MD: Rowman \& Littlefield

Xueqing, Jiang. (2012). "Internet Movie Fans Fear Twist in the Tale" terarsip dalam http://www.chinadaily.com.cn/china/2010-11/18/content_11566608.htm diakses pada 18 November 2012

Yar, Majid. (2008). "The Rethoric and Myth of Anti-Piracy Campaign: Criminalization, Moral Pedagogy, and Capitalist Property Relation in the Classroom" dalam New Media \& Society Vol. 10(4) 
